\title{
Discussion to the paper by J. S. Stewart
}

\section{Chatrman: Professor P. Fourman}

Chairman. I am a little concerned about these regressions we have been seeing this afternoon. They are significant, I don't know whether this is visible, they are significant at 0.05 on about ten points. The first thing is that any one point going off one way or another could change the whole picture of one out of ten. So 0.05 for ten points is just not secure. But the other thing that worries me a little bit is, you have a bunch of controls which are randomly distributed with respect to the independent variable, and then you have a bunch of abnormal values. I'm not saying this necessarily applies, you understand, but it looks to me as if it might. These would be randomly distributed with respect to the independent variable but in a different place, and then in an effort to get a correlation which is significant. Unless you can show the correlation of this within each group you have not persuaded a lot of people.

STEWART. With regard to the correlation which we think exists between the absorption of Vitamin $\mathbf{B}_{12}$ and ileal surface cell-height, I would agree entirely that we have too small numbers yet. This is just a suggestion. But the correlation between the severity of steatorrhoea $P<0.001$, I'm sure is all right.

Chairman. Yes quite, and there you see your whole correlation existed within the independent group within the abnormal group-you weren't relying on half your points being within the normal group.

SteWART. Yes, although all these patients, in the $B_{12}$ and the ileal cell-heights group, they all had idiopathic steatorrhoea and it is known that about a third of these patients with this condition do malabsorb $\mathbf{B}_{\mathbf{1 2}}$.

Chairman. Yes that was fine. You will forgive me for pointing to what is really a technical point. Anyway, in the hope that somebody will now be ready with an honest question.

Morgan. I'm going to ask what is Dr Stewart's definition of idiopathic steatorrhoea?

STEWART. I was afraid that somebody was going to ask me that question and I would say that idiopathic steatorrhoea is a condition in which there is a mucosal lesion maximal proximally and malabsorption. I wouldn't like to go very much futher than that. In other words it is almost certainly a mixed bag. I don't think it would be possible to demonstrate that all these patients have exactly the same condition. Their variation in response to gluten-free diet is very great. I think that a mucosal lesion maximal proximally excludes non-tropical sprue. You are still left of course with the difficulty of the patients with skin lesions and many other conditions which appear to be associated with abnormal biopsies. Most patients with idiopathic steatorrhoea, however, have a flat or flat mosaic biopsy whereas most of the other conditions are associated with partial villous atrophy.

WATKINSON. I wonder if Dr Stewart would comfort some of us who less frequently attempt intestinal biopsy and give us some practical details about the Crosby capsule? The difficulties of assembling it in poor light, losing the spiral spring on the floor, finding the capsule has fired on the way down, finding that it grips on to the mucosa like a terrier and won't let go till it sloughs off in a few days. Do you have these problems? How often have you used the Cook tube which is merely a hole with sharp edges which is much simpler but we don't know if it is as successful?

STEWART. We have stuck to the Crosby capsule because, I think by sheer good luck, we have been fortunate in having a very good capsule. A lot of the correspondence in the Lancet on this has made this point that capsule to capsule variation is very great. We have of course had a lot of problems and we prefer to assemble them in good light, etc. The main problem that we have had is difficulty in getting through the pylorus, in which case we tend to put it down the night before. I don't think anti-spasmodics make very much difference; sometimes hanging on to the mucosa and as you say, refusing to let go- this has happened twice in about 350 biopsies. Once it did come away after $1 \mathrm{hr}$ or so, another time we just had to cut the tube and take X-rays of the cartons of stools over the next few days, the easiest way to find it. We have had post-biopsy pain and fever but there has never been gas under the diaphragm on a plain X-ray and so the patient has not needed surgery. Post-biopsy fever occurred in three out of the 350 .

We have had bleeding necessitating transfusion of 2 pints, in two patients. Otherwise we have had no morbidity, In adults there is no reported mortality in the world literature. But of course there was the 18-month-old baby who died as a result of a Crosby capsule biopsy.

Because of the way the capsule works (and at the West Middlesex the experience has been very similar) we have stuck to a Crosby capsule.

WATKINSON We have had a similar experience with an American one which was smuggled here and it worked very well but a British copy has given nothing but trouble.

Question. We've been using the Crosby capsule, and we've done over 100 biopsies so far, touch wood, we haven't had any damage or perforations nor has it stuck more than $10 \mathrm{~min}$. Just one point, to comment on the fact that the normal variation in histology may in fact be due to changes in the flora in the bowel.

STEWART. This is in the control subjects? These controls were specially chosen because they did not have any symptoms or signs of anything affecting the gastrointestinal tract and so we did not do bacteriological studies on their small intestines.

Chairman. It varies throughout the world.

STEWART. Yes, I think there are several factors throughout the world. In East Africa and India and Thailand especially, just because reports have come from there, convoluted mucosa seems to be a very common finding. They have tried to relate it to dietary habits, to malnutrition and as you say bacterial characteristics of the gut, but I think that work is still in progress really, I don't think anybody really knows the answer. 